\title{
OCCUPATIONAL EXPOSURE TO SECOND HAND SMOKE AND RESPIRATORY AND SENSORY SYMPTOMS: A CROSS-SECTIONAL SURVEY OF HOSPITAL WORKERS IN EGYPT
}

GHADA N. RADWAN ${ }^{1}$, SAHAR LATIF ${ }^{2}$, NAHLA AMIN ${ }^{3}$, DALIA GALAL ${ }^{2}$, MAHA AZIZ ${ }^{2}$, and EHAB ATTIA ${ }^{4}$

${ }^{1}$ The International Union Against Tuberculosis and Lung Disease, Cairo, Egypt

Public Health Department, Faculty of Medicine, Cairo, Egypt

${ }^{2}$ Ministry of Health and Population, Egypt

Tobacco Control Department

${ }^{3}$ Tobacco Control Coalition, Egypt

${ }^{4}$ Ministry of Health and Population, Egypt

Environmental Health Sector

\begin{abstract}
Objective: Exposure to Second Hand Smoke (SHS) has been associated with an increased risk of respiratory symptoms, upper and lower respiratory tract diseases and an increased risk of asthma and chronic obstructive pulmonary disease. The majority of cases of mortality and morbidity is attributable to exposure of adults to SHS and is related to cardiovascular diseases and lung cancer. In Egypt, comprehensive smoke-free laws exist, however, in many workplaces they are poorly enforced consequently exposing workers to the detrimental health hazards of SHS. We aimed at determination of workplace exposure to Second Hand Smoke (SHS) and its association with respiratory and sensory irritation symptoms in hospital workers in Port-said governorate in Egypt. Material and Methods: A cross-sectional face to face survey was conducted by the use of a standardised questionnaire among 415 adult hospital workers; representing $50 \%$ of all employees (81\% response rate); recruited from 4 randomly selected general hospitals in Port-said governorate in Egypt. Results: All hospitals employees reported exposure to SHS - on average 1.5 (SD = 2.5) hours of exposure per day. After controlling for potential confounders, exposure to SHS at work was significantly associated with an increased risk of wheezes $(\mathrm{OR}=1.14, \mathrm{p}<0.01)$, shortness of breath $(\mathrm{OR}=1.17, \mathrm{p}<0.01)$, phlegm $(\mathrm{OR}=1.23, \mathrm{p}<0.01)$, running and irritated nose $(\mathrm{OR}=1.14, \mathrm{p}<0.01)$ as well as a sore, scratchy throat $(\mathrm{OR}=1.23)$. Conclusions: These findings point out that workplace exposure to SHS is evident in hospitals in Port-said governorate and that workers are adversely affected by exposure to it at work. This underlines the importance of rigorous enforcement of smoke-free policies to protect the workers' health in Egypt.
\end{abstract}

Key words:

Second hand smoke, Respiratory and sensory irritation symptoms, Attitudes, Smoke-free policies

This work was supported by Bloomberg Initiative grants number OC 400 and Egypt 4-01.

Received: March 1, 2013. Accepted: December 30, 2013.

Corresponding author: G. Radwan, Faculty of Medicine, Cairo University, The Union Middle East, The International Union Against Tuberculosis and Lung Disease (The Union), 11 Hassan Sadek, Heliopolis, El Merghany, Cairo, Egypt (e-mail: gnasr@theunion.org). 


\section{INTRODUCTION}

Exposure to Second Hand Smoke (SHS), which is a complex mixture of aerosols, vapours and hundreds of chemical compounds which has been classified as a human (group A) lung carcinogen [1,2]. Exposure to SHS has been associated with an increased risk of respiratory symptoms [3], upper and lower respiratory tract diseases and an increased risk of asthma, chronic obstructive pulmonary disease and lung cancer [4]. Globally, nearly two thirds of the world's population still allow smoking in workplaces consequently exposing the majority of workers to detrimental health hazards of SHS. The World Health Organization has estimated that each year workplace exposure to SHS causes 200000 deaths among employees and that 1 in 7 work-related deaths are attributable to chronic exposure to SHS [5]. On the other hand, there is consistent evidence that smoking bans have reduced exposure to SHS in workplaces, restaurants, pubs and in public places [6].

Strong evidence links implementation of $100 \%$ smoke-free legislation with a reduction of respiratory symptoms [7]. Several studies have evaluated respiratory symptoms before and after implementation of $100 \%$ smoke-free laws. All of these studies have shown a significant improvement in respiratory symptoms after implementation of $100 \%$ smoke-free policies [8]. However, most of these studies have been conducted in developed countries and focused mainly on hospitality workers [9].

Egypt ratified the Framework Convention on Tobacco Control (FCTC) in 2005 and in 2007 introduced a comprehensive smoke-free legislation that bans smoking in all public places including health care facilities. However, effective enforcement has remained a challenge. As in many developing countries, tobacco use and exposure to SHS are not perceived as a priority health problem [10]. Lack of national evidence on detrimental effects of exposure to SHS in public places might contribute to this faulty perception. The Union Middle East Office in collaboration with the Ministry of Health and Population (MOHP) and National Tobacco Control Coalition in Egypt aimed at determining workplace exposure to SHS and its association with respiratory and sensory irritation symptoms. We have also explored health care workers' attitudes towards smoke-free policies in hospitals and their impact on workers' job performance. The results of this study will provide the necessary evidence to drive the efforts towards effective enforcement of the existing smoke-free laws.

\section{METHODS}

A cross-sectional survey was conducted in 2011 in 4 randomly selected general hospitals in Port-said (total number $=11$, one Psychiatric Hospital was excluded). We estimated a sample consisting of 400 subjects based on the reported prevalence of exposure to SHS in their workplaces in a recent national survey [11]. The eligibility criteria for the study were, as follows: 18-year old or older employees, employed for a year or more on the current post. In each of the selected hospitals a census of all the employees was obtained from the National Information Centre in MOHP. A sample of $50 \%$ from each job category was randomly selected which yielded a sample of 513 workers for the current survey. Data collection was conducted by trained NGOs members residing in Port-said city. Official permissions to access selected hospitals as well as official approval to conduct the survey were obtained from MOHP. Prior to data collection, the data collectors obtained verbal consents and only then did they conduct face-to face interviews using an anonymous standard questionnaire to ensure confidentiality.

\section{Measures}

Healthcare workers provided information concerning demographics, smoking habits, their attitudes towards smoke-free policies in health care settings and their beliefs on how those would influence their job performance and the public image of their hospitals, hours of exposure 
to SHS at work and home as well as respiratory and sensory irritation symptoms.

Exposure to SHS was evaluated by asking "How often are you exposed to SHS in the indoor workplace?" and "How many hours indoors at work are you exposed to other people's tobacco smoke?". The respondents who self-reported $0 \mathrm{~h}$ of exposure were classified as not exposed, while the others were classified as exposed. To measure SHS exposure at home, the participants were asked "Do you live in one household with someone who smokes tobacco?" and "How many hours per day are you exposed to other people's smoke at home?".

We used the International Union against Tuberculosis and Lung Disease's Bronchial Symptoms Questionnaire to assess the respiratory and sensory health effects of SHS exposure [12]. Five upper respiratory symptoms were surveyed, including: wheezing, dyspnea, morning cough, cough during the rest of the day or night and phlegm production. Three sensory symptoms were surveyed including: red or irritated eyes; a runny nose, sneezing or nasal mucus; a sore throat. The respondents were asked if they had experienced any of the above symptoms in the previous 4 weeks. To assess the presence of other conditions, including those that could potentially induce these symptoms, the participants were also asked whether they had doctor confirmed asthma or any other health conditions that caused respiratory problems.

The interviewed employees were categorized as either current tobacco smokers or non-smokers. Current cigarette smokers were defined as those who had ever smoked more than 100 cigarettes in their life and had smoked during the time of the survey [13] and current shisha (water pipe) smokers were those who smoked during the time of the survey.

\section{Statistical analysis}

Initially a descriptive data analysis was undertaken. Categorical variables were compared between the groups using the Pearson $\mathrm{Chi}^{2}$ test. Categorical data were described as frequencies and percentages. Continuous data were described as a mean and standard deviation (SD). Logistic regression models (using the enter method) were used to investigate the association of respiratory and sensory symptoms (each symptom as a dependent variable) and "hours of exposure to SHS at work" (predictor variable) after adjusting for possible confounding factors.

The control variables included in the analyses were: presence of asthma or other respiratory problems, smoking status, home SHS exposure, age, gender, occupation and education. The odds ratio of logistic regression models represented the odds of having a respiratory/sensory symptom with one more hour of exposure to SHS at work, controlling for the aforementioned covariates. Another regression model similar to the one described above was developed but with "the hours of exposure to SHS at work and home" as the predictor variable. All statistical tests were 2-sided with $\alpha=0.05$. SPSS V.16.0 (SPSS, Chicago, USA) was used to analyse the data analysis.

\section{RESULTS}

\section{Characteristics of the respondents}

Of the 513 targeted workers 415 responded to the survey (response rate $81 \%$ ) with the age range between 20-60 years. More than a half of the respondents were females (64\%). The most frequent occupations reported by the respondents were administrative jobs. Physicians represented nearly one fifth of the study group (33\% and 19\% respectively) (Table 1).

$9 \%$ and $3.1 \%$ of the respondents were current cigarette and current shisha smokers, respectively. The smoking behaviour was significantly associated with male gender ( $24 \%$ vs. $0.4 \% \mathrm{p}=0.000$ for cigarette smoking, $8.2 \%$ vs. $0.4 \% \mathrm{p}<0.001$ for shisha smoking). No significant association of smoking behaviour was observed in relation to education level $(\mathrm{p}>0.05)$. However, we found 
Table 1. Demographics, smoking habits and attitudes towards the smoke-free policies of health care workers

\begin{tabular}{|c|c|}
\hline Variables & $\begin{array}{l}\text { Study group } \\
(\mathrm{N}=415)\end{array}$ \\
\hline Age $(\mathrm{M} \pm \mathrm{SD})$ & $38.4 \pm 11.4$ \\
\hline \multicolumn{2}{|l|}{ Gender (n, \%) } \\
\hline male & $146(35.2)$ \\
\hline female & $269(64.8)$ \\
\hline \multicolumn{2}{|l|}{ Occupation (n, \%) } \\
\hline physician & $77(18.6)$ \\
\hline pharmacist & $46(11.1)$ \\
\hline technician & $85(20.6)$ \\
\hline nurse & $69(16.7)$ \\
\hline administrative employee & $136(32.9)$ \\
\hline \multicolumn{2}{|l|}{ Education (n, \%) } \\
\hline preparatory and below & $28(6.7)$ \\
\hline intermediary & $215(51.8)$ \\
\hline college and above & $172(41.4)$ \\
\hline \multicolumn{2}{|l|}{ Shisha smoking status (n, \%) } \\
\hline non-smokers & $402(96.9)$ \\
\hline current smokers & $13(3.1)$ \\
\hline \multicolumn{2}{|l|}{ Cigarette smoking status (n, \%) } \\
\hline non-smokers & $379(91.3)$ \\
\hline current smokers & $36(8.7)$ \\
\hline \multicolumn{2}{|c|}{ Does your job involve direct patient care or contact (n, \%) } \\
\hline yes & $285(68.7)$ \\
\hline \multicolumn{2}{|c|}{ The extent of support to SF policies if implemented in the workplace (n, \%) } \\
\hline agree & $397(95.90)$ \\
\hline \multicolumn{2}{|c|}{ The effect of smoking ban in the workplace on job performance (n, \%) } \\
\hline improve & $354(85.30)$ \\
\hline worsen & $20(4.80)$ \\
\hline no effect & $41(9.90)$ \\
\hline current smokers (cigarette) & $25(69.40 * * \#)$ \\
\hline non-smokers & $329(86.80)$ \\
\hline males & $121\left(82.90^{* * \#)}\right.$ \\
\hline females & $233(86.60)$ \\
\hline preparatory and below & $27\left(96.40^{* * \#)}\right.$ \\
\hline intermediary & $188(87.40)$ \\
\hline college and above & $139(80.80)$ \\
\hline physicians & $57(74.02 * *)$ \\
\hline
\end{tabular}


Table 1. Demographics, smoking habits and attitudes towards the smoke-free policies of health care workers - cont.

\begin{tabular}{lc}
\multicolumn{1}{c}{ Variables } & $\begin{array}{c}\text { Study group } \\
(\mathrm{N}=415)\end{array}$ \\
\hline pharmacists & $42(91.30)$ \\
technicians & $71(83.52)$ \\
nurses & $61(88.40)$ \\
administrative employees & $122(89.70)$ \\
The effect of smoking ban in the workplace on hospital's public image (n, \%) & $397(96.40)$ \\
agree & $7(1.70)$ \\
disagree & $8(1.90)$ \\
no difference & \\
\hline
\end{tabular}

M - mean; SD - standard deviation.

$*$ p of Chi test.

** Persons believe that smoking ban would improve their job performance across different categories.

$\# \mathrm{p}<0.05$.

a significant association between cigarette smoking behaviour and occupation; with the highest smoking prevalence among physicians (16.9\% vs. $12.9 \%$ technicians, $5.8 \%$ nurses, $5.9 \%$ administrative employees, $\mathrm{p}<0.01$, data are not shown).

\section{Self-reported exposure to SHS}

All the respondents reported exposure to SHS at work. 58\% of the respondents $(\mathrm{N}=242)$ graded their exposure as being very frequent or frequent. Mean duration of exposure to SHS at work was 1.5 (SD \pm 2.6 ) hours (Figure 1).

No significant difference in the exposure to SHS at work was observed between males and females ( $p>0.05)$. However, nurses and administrative employees reported higher levels of exposure to SHS at work compared to other groups - hours of exposure were (mean \pm standard deviation): $2.1 \pm 2.7$ nurses, $2.1 \pm 3.2$ administrative, $1.1 \pm 2.2$ physicians, $1 \pm 1.4$ pharmacists and $0.9 \pm 2$ technicians $(\mathrm{p}=0.002)$.

With respect to exposure at home, nearly one third of the respondents reported the presence of one or more smokers at home (33\%). However, all the respondents reported daily exposure to SHS at home with a mean duration of exposure of $1.3( \pm 4)$ hours daily.

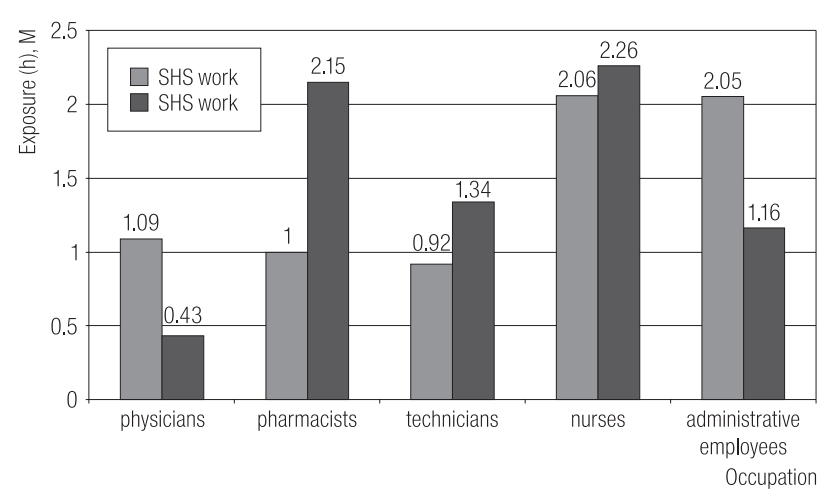

$\mathrm{M}-$ mean.

Fig. 1. Exposure to second hand smoke (SHS) at work and home by different occupation categories

\section{Health workers' attitudes towards SHS and smoke-free policies}

The vast majority of respondents $(95.6 \%)$ unanimously supported smoke-free policies implementation in the workplace and $85 \%$ believed that smoke-free policies will improve their job performance. This beliefs significantly differed depending on gender, education, occupation and smoking status (Table 1).

Nearly all the interviewed health care workers believed that health professionals serve as role models for the 


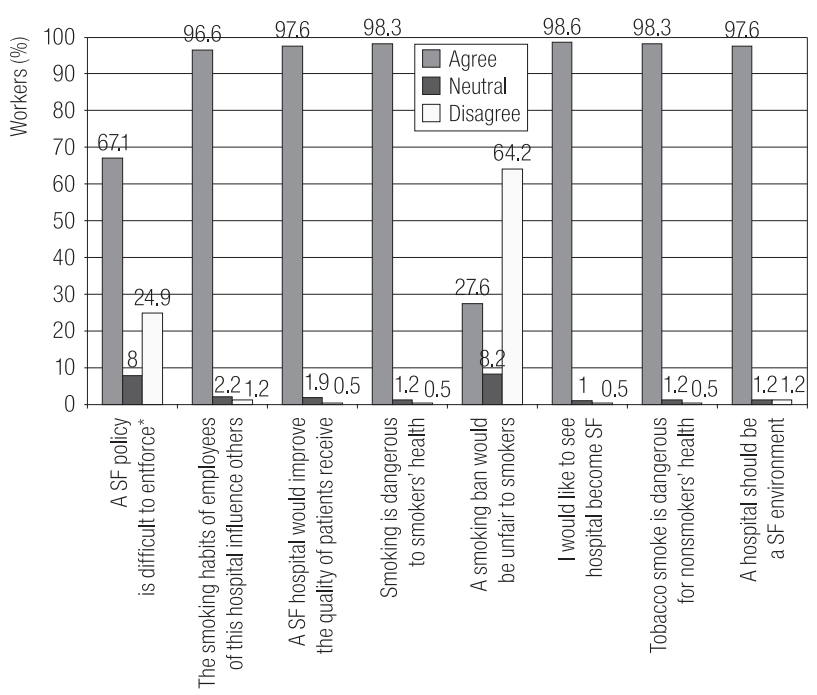

* Larger proportion of females believed it is enforceable compared to males, $\mathrm{p}<0.05$.

Fig. 2. Health workers' attitude towards exposure to second hand smoke (SHS) and smoke-free policies

public and patients (99\%) and $92 \%$ of them professed that health professionals should routinely advise their patients who smoke to quit. However, $64 \%$ of the respondents were taught in their classes about dangers of smoking. And less than one third of the respondents (28\%) have received formal training in smoking-cessation approaches (data not shown).

The questions concerning attitude (Figure 2) were compared with regard to the gender, education, occupation and smoking status. We found significant gender differences in the perception of how difficult the enforcement of smoke-free policies within the hospital is i.e. compared to males larger proportion of females believed it is enforceable (28.7 vs. $17.8 \%, p=0.04)$

\section{Prevalence of respiratory}

\section{and sensory irritation symptoms}

Nearly half of the respondents (48.1\%) reported the presence of at least respiratory irritation symptoms and $40 \%$ reported one or more sensory irritation symptoms during the past 4 weeks of the interview.
The most prevalent respiratory symptoms were shortness of breath $(13 \%)$ followed by cough first thing in the morning $(8.9 \%)$. One in 10 respondents reported one of the sensory irritation symptoms $(14.5 \%$ - red or irritated eyes, $13 \%$ - a sore or scratchy throat, $12.5 \%$ - a running nose, sneezing or nose irritation).

Logistic regression analysis was used to examine association between hours of workplace SHS exposure per day (predictor variable) and each respiratory and sensory symptom (dependent variable). Potential confounders that we adjusted for are listed in Table 2.

The OR (Table 2) represented the odds of having each symptom with one more hour of exposure to SHS, controlling for potential covariates. The results showed that the average hours of SHS exposure in the workplace were positively associated with all the evaluated respiratory and sensory irritation symptoms, except for cough symptoms and red irritated eyes. The odds of suffering from any symptom increased by at least $12 \%$ (OR $=1.13-1.23$, $\mathrm{p}<0.05$ ) along with one more hour of exposure to SHS per day. For example, the odds of phlegm increased

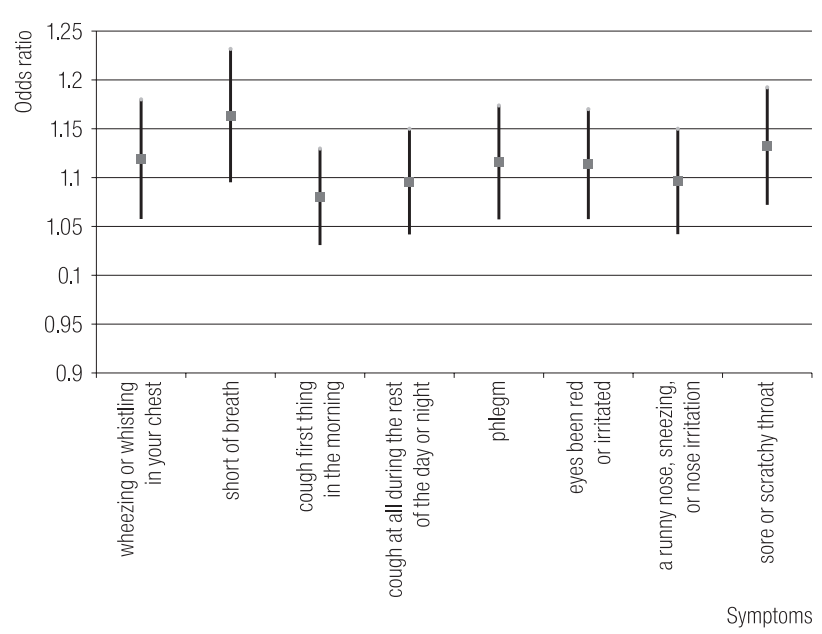

The values (odds ratio) presented are adjusted for age, sex, occupation, education and smoking status.

Fig. 3. Association between hours of exposure to second hand smoke (SHS) in the workplace and home, and respiratory and sensory irritation symptoms 
Table 2. Adjusted odds ratios (OR) for the association between respiratory and sensory irritation symptoms and hours of exposure to second hand smoke (SHS) in the workplace using logistic regression analysis $(\mathrm{N}=413)$

\begin{tabular}{|c|c|c|c|c|c|}
\hline \multirow{2}{*}{ Respiratory/sensory symptom } & \multirow{2}{*}{$\mathrm{p}$} & \multirow{2}{*}{$\mathrm{B}(\mathrm{SE})$} & \multirow{2}{*}{$\mathrm{OR}^{*}$} & \multicolumn{2}{|c|}{$95 \%$ CI for $\operatorname{EXP}(B) * *$} \\
\hline & & & & upper & lower \\
\hline Wheezing or whistling in your chest & 0.007 & $0.13(0.05)$ & 1.144 & 1.037 & 1.262 \\
\hline Shortness of breath & 0.001 & $0.16(0.05)$ & 1.178 & 1.067 & 1.301 \\
\hline Cough first thing in the morning & 0.944 & $0.04(0.05)$ & 1.004 & 0.907 & 1.111 \\
\hline Cough all during the rest of the day or night & 0.052 & $0.09(0.05)$ & 1.104 & 0.999 & 1.221 \\
\hline Phlegm & 0.000 & $0.21(0.05)$ & 1.231 & 1.108 & 1.367 \\
\hline Eyes been red or irritated & 0.125 & $0.07(0.05)$ & 1.080 & 0.979 & 1.191 \\
\hline A runny nose, sneezing, or nose irritation & 0.005 & $0.14(0.05)$ & 1.146 & 1.043 & 1.259 \\
\hline Sore or scratchy throat & 0.016 & $0.12(0.05)$ & 1.128 & 1.023 & 1.245 \\
\hline
\end{tabular}

B (SE) - regression coefficients and their standard errors.

* Adjusted odd ratios (OR) of exposure to SHS at work (continuous variable).

** The model has the symptom of interest as dependent variable (binary), and independent variable included are exposure to SHS at work (continuous), age (continuous), sex (binary), occupation (categorical), education (categorical) SHS exposure at home (continuous), asthma (binary) and smoking of either cigarettes or shisha (current vs. non-smokers).

$\mathrm{CI}$ - confidence interval.

by $23 \%$ with one more hour of exposure to SHS at work $(\mathrm{OR}=1.23)$ (Table 2).

However, the regression model with "hours of SHS exposure at work and home" as a predictor, revealed a positive significant association between the average hours of SHS exposure and all the examined respiratory and sensory irritation symptoms $(\mathrm{p}<0.001)$ (Figure 3).

\section{DISCUSSION}

SHS is a significant risk factor for the development of many diseases, including: lung cancer, lower respiratory tract infections, asthma and eye, throat and nasal irritations [14]. It has been reported that the most common acute effects of exposure to SHS are sensory irritation of the eyes, nose, throat, and airways that tend to be enhanced with both increasing concentration and increasing duration of exposure [15]. In addition, available scientific data suggest that workplace exposure may be more detrimental to health than domestic exposure [16]. For example, Janson et al. (2001) reported that the association between passive smoking and respiratory symptoms and asthma was much stronger if the exposure occurred at work than at home [16,17]. Egypt was an early signatory to the FCTC, having ratified it in February of 2005. In 2007, the adoption of new tobacco control laws paved the way for Egypt to meet its obligations under the FCTC. The law clearly bans smoking in all public places including health care facilities. However, a key challenge to the implementation of these laws is that they are inadequately enforced. Taking into account health consequences of SHS exposure and high prevalence of exposure in workplaces, many countries have implemented the smoking ban that prohibits smoking in workplaces, including restaurants and bars [14]. In Egypt, although considerable achievements have been made in creating a smoke-free environment, there is still a big gap between the enforcement and the standards set out in the FCTC. The current study was conducted aiming at providing domestic data on exposure to SHS in the workplaces and the associated acute respiratory and sensory effects. The current study findings will be presented to decision makers to create the momentum 
necessary for effective and prompt enforcement of the existing smoke-free laws.

The study has revealed several key findings. Firstly, all the interviewed health workers were exposed to SHS and more than half of them $(58 \%)$ reported frequent exposure in their workplaces. Global Adult Tobacco Survey 2009 in Egypt found that nearly two thirds of all indoor workers $(61 \%)$ were exposed to SHS at work and nearly $59 \%$ of them were non-smokers [11]. These results underpin the urgent need to effectively enforce smoke-free laws in Egypt which are either weakly enforced or not enforced at all in the majority of workplaces and public places.

Secondly, we have found that nearly half of the interviewed hospital workers reported at least one sensory $(40 \%)$ and respiratory $(48 \%)$ irritation symptom in the previous 4 weeks. The association between sensory and respiratory symptoms and exposure to SHS is consistent with other studies of workers $[18,19]$. Furthermore, 5 respiratory and sensory symptoms were associated with exposure to SHS. The odds of having any of those symptoms increased at least by $12 \%$ along with one hour of exposure to SHS at the workplace after adjusting for potential confounders (Table 2), which adds to evidence that exposure to SHS is associated with poor respiratory and sensory symptoms [18,20].

This finding also provides evidence to support the establishment of smoke-free policy in the workplaces which have been shown to make a substantial difference in the concentration of SHS in the workplace [9,21]. An Ontario study of 180 public sites determined that 1 year after implementation of smoking restrictions, there was an overall decrease in SHS of about two thirds across all the tested sites [22].

Moreover, epidemiological studies have clearly demonstrated that implementation of the smoke-free legislation was associated with a substantial and rapid reduction of respiratory and sensory irritation symptoms [14,23]. For example, bar workers in Scotland reported significantly fewer symptoms 1 year after their working environment became smoke free [20]. In another study in Ireland, there were substantial declines in self-reported respiratory irritation symptoms in the wake of the smoke-free legislation reaching $18.6 \%$ for smokers, and $33.2 \%$ for non-smokers; likewise sensory symptoms declined up to $17.7 \%$ for smokers and up to $46.8 \%$ for non-smokers [24]. Although, most of these studies focused on hospitality venues, they are consistent with our study in terms of aiming at assessment of exposure to SHS in indoor workplaces that should be $100 \%$ smoke-free.

It is noteworthy that only $100 \%$ ban of smoking offered protection from harmful health effects of SHS. Fernández et al. (2009) reported that at the venues where smoking was completely prohibited, a significant reduction in selfreported exposure to SHS and respiratory symptoms was observed, whereas no changes were seen in workers at the venues where smoking was only partially restricted or permitted throughout the premises [25].

Thirdly, we have found a high level of support for the $100 \%$ smoke-free law among workers (96\%) which is consistent with similar surveys [23]. In a national survey conducted in 13 Argentine cities, $96 \%$ of general population were supportive to $100 \%$ smoke-free legislation [26].

\section{LIMITATIONS}

Using simple randomization and stratified randomization techniques in selecting general hospitals and employees within selected hospitals; representing nearly $50 \%$ of all hospitals and employees respectively are amongst the strengths of the current study. However, the study has several limitations associated with its cross-sectional design. Uncertainty of temporal sequence between exposure and outcome variables and recall bias are the examples of such limitations. However, several prospective studies have confirmed the causal association of workplace exposure to SHS and the frequency of respiratory symptoms [27]. 
Many other studies have confirmed that self-reported exposure is a valid measure being consistent with biological markers such as urinary and salivary cotinine [28]. Finally, we used respiratory and sensory irritation symptoms as indicators of acute health effects of SHS. Symptoms such as coughing could also be associated with other causes, such as bacterial and viral infections. Although, we controlled for the presence of asthma or other respiratory conditions in our statistical analysis, there remains the possibility of effects due to unmeasured confounders or effect modifiers e.g. other indoor air pollutants.

\section{CONCLUSIONS}

Despite existence of smoke-free laws, this study has found that hospital workers in Port-said governorate in Egypt are still exposed to the detrimental short term outcomes of exposure to the SHS (sensory and respiratory irritation symptoms) which adds to the body of literature supporting the relationship between SHS and adverse health consequences among smokers and non-smokers.

Furthermore, the undertaking of this study is greatly important for promoting $100 \%$ smoke-free law enforcement in the workplaces in Egypt as a legitimate right of workers, and to reduce social acceptance of smoking in workplaces and public places. Media coverage of the study results would have a great impact and decision makers would be able to use this evidence as the basis of effective prompt enforcement of the smoke-free law.

\section{ACKNOWLEDGMENT}

We thank Dr Samar El-Fekhy the former CTC Project Coordinator and the Egyptian National Coalition NGOs in Port-said (Association for Women's Development, Safe Community Association, Port-said Cultural and Social Development Association, Red Crescent Association, Media Association and Business
Women Association in Port-Said) for carrying out the field work for this study. Dr. Nabiel Mikhail provided data management support and supervised the data entry.

\section{REFERENCES}

1. EPA. Respiratory health effects of passive smoking: lung cancer and other disorders. Bethesda (MD): US Environmental Protection Agency, US Department of Health, Public Health Service, National Institute of Health; 1993. Contract No. 93-3605.

2. International Agency for Research on Cancer. Monographs on the Evaluation of Carcinogenic Risks to Humans. Vol. 83 Tobacco Smoke and Involuntary Smoking 2004. Geneva: World Health Organization; 2004.

3. Simoni M, Baldacci S, Puntoni R, Pistelli F, Farchi S, Lo Presti E, et al. Respiratory symptoms/diseases and environmental tobacco smoke (ETS) in never smoker Italian women. Respir Med. 2007;101(3):531-8, http://dx.doi.org/10.1016/ j.rmed.2006.06.021.

4. Brennan P, Buffler PA, Reynolds P, Wu AH, Wichmann HE, Agudo A, et al. Secondhand smoke exposure in adulthood and risk of lung cancer among never smokers: A pooled analysis of two large studies. Int J Cancer. 2004;109(1):125-31, http://dx.doi.org/10.1002/ijc.11682.

5. World Health Organization. Report on the Global Tobacco Epidemic, 2008: The MPOWER package. Geneva: WHO; 2008 [cited 2013 Jan 1]. Available from: http://www.who.int/ tobacco/mpower/mpower_report_full_2008.pdf.

6. Callinan JE, Clarke A, Doherty K, Kelleher C. Legislative smoking bans for reducing secondhand smoke exposure, smoking prevalence and tobacco consumption. Cochrane Database Syst Rev. 2010(4):CD005992.

7. Pell JP, Haw S, Cobbe S, Newby DE, Pell AC, Fischbacher C, et al. Smoke-free legislation and hospitalizations for acute coronary syndrome. N Engl J Med. 2008;359(5):482-91, http://dx.doi.org/10.1056/NEJMsa0706740.

8. Menzies D, Nair A, Williamson PA, Schembri S, Al-Khairalla MZ, Barnes M, et al. Respiratory symptoms, pulmonary 
function, and markers of inflammation among bar workers before and after a legislative ban on smoking in public places. JAMA. 2006;11;296(14):1742-8, http://dx.doi. org/10.1001/jama.296.14.1742.

9. Polańska K, Hanke W, Konieczko K. [Hospitality workers' exposure to environmental tobacco smoke before and after implementation of smoking ban in public places: A review of epidemiological studies]. Med Pr. 2011;62(2):211-24. Polish.

10. World Health Organization. Building blocks for tobacco control: A handbook. Geneva: WHO; 2004.

11. Centers for Disease Control and Prevention. The Global Adult Tobacco Survey (GATS), Egypt - Fact Sheets. Atlanta GA: CDC; 2010 [cited 2012 Dec 1]. Available from: http:// wwwcdcgov/tobacco/global/gats/countries/emr/fact_sheets/ egypt.

12. Burney PG, Laitinen LA, Perdrizet S, Huckauf H, Tattersfield AE, Chinn S, et al. Validity and repeatability of the IUATLD (1984) Bronchial Symptoms Questionnaire: An international comparison. Eur Respir J. 1989;2(10): 940-5.

13. Centers for Disease Control and Prevention. Cigarette Smoking Among Adults - United States, 2003, May 27. CDC; 2005;54(20);509-13.

14. Polańska K, Hanke W, Konieczko K. [Impact of the legislation for smoke-free workplaces on respiratory health in hospitality workers - review of epidemiological studies]. Med Pr. 2011;62(3):297-308. Polish.

15. Eisner MD, Katz PP, Yelin EH, Hammond SK, Blanc PD. Measurement of environmental tobacco smoke exposure among adults with asthma. Environ Health Perspect. 2001; 109(8):809-14, http://dx.doi.org/10.1289/ehp.01109809.

16. Janson C. The effect of passive smoking on respiratory health in children and adults. Int J Tuberc Lung Dis. 2004;8(5): 510-6.

17. Janson C, Chinn S, Jarvis D, Zock JP, Toren K, Burney P. Effect of passive smoking on respiratory symptoms, bronchial responsiveness, lung function, and total serum $\operatorname{IgE}$ in the European Community Respiratory Health Survey:
A cross-sectional study. Lancet. 2001;358(9299):2103-9, http://dx.doi.org/10.1016/S0140-6736 (01) 07214-2.

18. Pilkington PA, Gray S, Gilmore AB. Health impacts of exposure to second hand smoke (SHS) amongst a highly exposed workforce: survey of London casino workers. BMC Public Health. 2007 [cited 2013 Jan 1];7:257. Available from: http:// www.ncbi.nlm.nih.gov/pmc/articles/PMC2040157.

19. Zheng P, Li W, Chapman S, Zhang Z, Gao J, Fu H. Workplace exposure to secondhand smoke and its association with respiratory symptoms - A cross-sectional study among workers in Shanghai. Tob Control. 2011;20(1):58-63, http:// dx.doi.org/10.1136/tc.2010.036921.

20. Ayres JG, Semple S, MacCalman L, Dempsey S, Hilton S, Hurley JF, et al. Bar workers' health and environmental tobacco smoke exposure (BHETSE): symptomatic improvement in bar staff following smoke-free legislation in Scotland. Occup Environ Med. 2009;66(5):339-46, http://dx.doi. org/10.1136/oem.2008.040311.

21. Hammond SK, Sorensen G, Youngstrom R, Ockene JK. Occupational exposure to environmental tobacco smoke. JAMA. 1995;274(12):956-60, http://dx.doi.org/10.1001/jama. 1995.03530120048040.

22. Abernathy T, O'Grady B, Dukeshire S. Changes in ETS following anti-smoking legislation. Can J Public Health. 1998;89(1):33-4.

23. Wakefield M, Cameron M, Inglis G, Letcher T, Durkin S. Secondhand smoke exposure and respiratory symptoms among casino, club, and office workers in Victoria, Australia. J Occup Environ Med. 2005;47(7):698-703, http://dx.doi. org/10.1097/01.jom.0000167285.33870.f9.

24. Bannon F, Devlin A, McElwee G, Gavin A. Greater gains from smoke-free legislation for non-smoking bar staff in Belfast. Eur J Public Health. 2009;19(6):638-43, http://dx.doi. org/10.1093/eurpub/ckp087.

25. Fernandez E, Fu M, Pascual JA, Lopez MJ, Perez-Rios M, Schiaffino A, et al. Impact of the Spanish smoking law on exposure to second-hand smoke and respiratory health in hospitality workers: A cohort study. PLoS 
One. 2009;4(1):e4244, http://dx.doi.org/10.1371/journal. pone. 0004244

26. Schoj V, Sebrie EM, Pizarro ME, Hyland A, Travers MJ. Informing effective smokefree policies in Argentina: air quality monitoring study in 15 cities (2007-2009). Salud Publica Mex. 2010;52 Suppl 2:S157-67, http://dx.doi.org/10.1590/ S0036-36342010000800011.

27. Ho SY, Lam TH, Chung SF, Lam TP. Cross-sectional and prospective associations between passive smoking and respiratory symptoms at the workplace. Ann Epidemiol. 2007;17(2):126-31, http://dx.doi.org/10.1016/j.annepidem.2006.06.010.

28. Semple S, Maccalman L, Naji AA, Dempsey S, Hilton S, Miller BG, et al. Bar workers' exposure to second-hand smoke: The effect of Scottish smoke-free legislation on occupational exposure. Ann Occup Hyg. 2007;51(7):571-80, http://dx.doi.org/10.1093/annhyg/mem044.

This work is available in Open Access model and licensed under a Creative Commons Attribution-NonCommercial 3.0 Poland License - http://creativecommons.org/ licenses/by-nc/3.0/pl/deed.en. 